\title{
Descrição de três novas espécies de Mahanarva (Hemiptera, Cercopidae, Ischnorhininae)
}

\author{
Andressa Paladini \& Gervásio Silva Carvalho
}

Laboratório de Entomologia, Departamento de Biodiversidade e Ecologia, Faculdade de Biociências, PUCRS. Av. Ipiranga, 6681, 90619900 Porto Alegre, RS. (andri_bio@yahoo.com.br; gervasio@pucrs.br)

\begin{abstract}
Description of three new species of Mahanarva (Hemiptera, Cercopidae, Ischnorhininae). Three new neotropical species of the spittlebug genus Mahanarva are described: M. (M.) rubrovenata, M. (M.) webbi e M. (M.) dabliosignata, all from Brazil.
\end{abstract}

KEYWORDS. Hemiptera, Mahanarva, spittlebugs, new species, Neotropical.

RESUMO. Três novas espécies de cigarrinhas neotropicais do gênero Mahanarva são descritas: $M$. (M.) rubrovenata, M. (M.) webbi e M. (M.) dabliosignata, todas do Brasil.

PALAVRAS-CHAVE. Hemiptera, Mahanarva, cigarrinhas, novas espécies, Neotropical.

Mahanarva foi descrito por Distant (1909), que elegeu como espécie-tipo Mahanarva indicata Distant, 1909. Sua descrição sucinta, baseada em uma fêmea cuja localidade é indicada apenas Brasil, refere-se somente à coloração e a poucas características morfológicas. O gênero é constituído atualmente por 39 espécies neotropicais, agrupadas em dois subgêneros, sendo 15 delas registradas para o Brasil.

FEnNah (1968) dividiu o gênero em dois subgêneros: Mahanarva s. str. e M. (Ipiranga). Segundo o autor, estes dois subgêneros podem ser diferenciados pela razão entre o comprimento e a largura, em tégminas largas e estreitas (três e maior que três). Conforme Carvalho \& Webb (2005), algumas espécies têm características comuns em ambos os subgêneros, como por exemplo, tégmina mais alongada em Mahanarva (Mahanarva).

Os insetos pertencentes a Mahanarva (Mahanarva) caracterizam-se por apresentar o posclípeo fortemente inflado, convexo, de perfil angulado (mais evidente nas fêmeas que nos machos), com carena longitudinal bem marcada e proeminente em algumas espécies e ranhuras laterais levemente marcadas. Pronoto largo, grosseiramente puncturado, com carena mediana fraca ou ausente. Tíbias posteriores com dois espinhos laterais, o basal muito pequeno. Ápice da tíbia com 15 espinhos distribuídos em duas fileiras; basitarso com 15 a 30 espinhos apicais em três ou mais fileiras; processo subungueal presente. Pigóforo com processos laterais entre o tubo anal e as placas subgenitais, que são alongadas, com ápice agudo. Edeago estreito, apresentando pouca variação entre as espécies, com dois processos dorsais longos e achatados, geralmente curvos apicalmente. Parâmero com ápice arredondado e espinho subapical em forma de gancho, fortemente esclerotizado e munido de dentículos na face interna. Primeira valva do ovipositor com processo basal desenvolvido.

$\mathrm{O}$ material estudado pertence às seguintes instituições: The Natural History Museum, London
(BMNH); Coleção "Pe. Jesus Santiago Moure", Departamento de Zoologia, Universidade Federal do Paraná, Curitiba (DZUP); Museu de Ciências Naturais da Fundação Zoobotânica do Rio Grande do Sul, Porto Alegre (MCNZ); Museu de Ciências e Tecnologia, Pontifícia Universidade Católica do Rio Grande do Sul, Porto Alegre (MCTP); Museu de Zoologia, Universidade de São Paulo, São Paulo (MZSP); Zoological Museum, University of Copenhagen, Copenhagen (ZMUC, anteriormente LUND). Os exemplares foram examinados sob estereomicroscópio e as medidas tomadas com ocular micrométrica. As peças da genitália foram destacadas, preparadas e fotografadas com Microscópio Eletrônico de Varredura, do Centro de Microscopia e Microanálises (CEMM) da PUCRS.

\section{Mahanarva (Mahanarva) rubrovenata sp. nov. (Figs. 1-16, 41, 44)}

Medidas (em mm). శ/\$. Comprimento da cabeça, 1/ 1,1; largura da cabeça, 2,2/2,3; diâmetro do ocelo, $0,1 / 0,1$; distância interocelar, $0,1 / 0,2$; distância ocelo-olho, $0,4 /$ 0,4; distância ocelo-tilo, 0,3/0,3; distância ocelo-margem posterior, 0,3/0,3; distância interocular, 1,3/1,4; comprimento do tilo, 0,4/0,3; largura do tilo, 0,6/0,7; comprimento do posclípeo, 1,5/1,5; largura do posclípeo, 0,8/0,9; comprimento do pronoto, 2,4/2,6; largura do pronoto, 3,9/4,3; comprimento do escutelo, 1,8/2,2; largura do escutelo, 1,4/1,6; comprimento da tégmina, 10,5/11,3; largura da tégmina, 3,3/3,3; comprimento total, 12,8/13,6.

Diagnose. Coloração geral negra; tégminas castanho-escuras, com as veias avermelhadas no terço basal e médio e duas máculas vermelho-claras no início do terço posterior. Tórax e abdômen negros com regiões castanho-claras. Pernas vermelhas, com tíbias e fêmures enegrecidos na face interna; tarsos negros (Figs. 41, 44).

Holótipo macho. Cabeça negra, mais larga que o comprimento do vértice, este convexo, com uma carena 
mediana bem marcada e proeminente; margens supraantenais avermelhadas; tilo quadrangular, negro, 1,2 vez mais largo que longo, com carena mediana aparente; ocelos castanho-dourados, separados entre si por uma distância igual a um diâmetro de um deles, mais próximos um do outro do que dos olhos e da margem posterior da cabeça; olhos castanho-escuros com a região periférica amarelada, proeminentes e dispostos transversalmente; antenas com pedicelo castanho-avermelhado, mais longo do que largo, não visível dorsalmente; corpo basal do flagelo negro, subcilíndrico, projetado para fora do pedicelo, com uma arista menor do que este; posclípeo negro, inflado, de perfil angulado, mais longo do que largo, com ranhuras laterais levemente marcadas; carena longitudinal distinta e proeminente, formando um triângulo no ápice com o tilo; anteclípeo negro, maior que o último artículo do rostro e este menor que o anterior; rostro atingindo as mesocoxas, com segundo artículo vermelho e o terceiro negro. Pronoto hexagonal, mais longo que largo, negro, grosseiramente puncturado e enrugado, com carena mediana levemente marcada, estendendo-se até o terço médio deste e apresentando duas impressões circulares na porção anterior; margem anterior reta, ântero-laterais convexas, póstero-laterais sinuosas e posterior chanfrada, com reentrância mediana; ângulos umerais arredondados; escutelo negro, mais longo do que largo, com concavidade mediana e rugosidades transversais. Tégminas estreitas, finamente puncturadas, de coloração castanho-escura, com as veias avermelhadas no terço basal e médio e duas máculas vermelho-claras situadas no terço posterior, anteriormente à porção reticulada da tégmina; a primeira localizada logo após as ramificações da veia $\mathrm{R}$ e a segunda na porção final da $\mathrm{Cu} 1 ; \mathrm{M}$ e $\mathrm{Cu} 1$ coalescidas no terço basal; reticulação apical bem desenvolvida, veias salientes; A1 e A2 bem distintas. Asas hialinas com venação castanhoescura; Cu1 não espessada na base. Pernas posteriores: fêmur com pequeno espinho na face interna; tíbia com dois espinhos laterais, sendo o basal menor que os apicais, estes em número de 15, distribuídos em duas fileiras; basitarso com aproximadamente 27 espinhos apicais, cobertos por longas cerdas; processo subungueal presente.

Pigóforo negro, com processos laterais arredondados e pouco desenvolvidos entre o tubo anal e as placas subgenitais (Fig. 1); estas largas na base, com o ápice arredondado, margem dorsal interna munida de um conjunto de dentículos arredondados (Figs. 2, 3); parâmeros sub-retangulares, com elevação dorsal desenvolvida e ápice arredondado, dente subapical robusto, voltado para fora e com formato de gancho, apresentando um conjunto de dentículos na face interna (Figs. 4, 5); edeago subcilíndrico, com haste longa, ápice truncado; processos dorsais comprimidos, curvos na extremidade, inseridos pouco acima da metade (Figs. 6-8).

Fêmea. Semelhante ao macho, um pouco maior e com posclípeo acentuadamente angulado. Ovipositor com primeira valva longa, delgada e ápice acuminado (Fig. 9), com processo basal arredondado, bem desenvolvido, voltado para baixo (Fig. 10); segunda valva longa, com ápice arredondado, apresentando em sua margem dorsal um conjunto de dentes estendido somente até o terço anterior, face externa com um conjunto de sensilas (Figs.11,12,14); face interna com ornamentações laminares (Fig. 15); terceira valva curta e larga, com longas cerdas na face ventral (Fig. 13) e ornamentações na face interna (Fig. 16).

Material-tipo. Holótipo đo, BRASIL, Rio de Janeiro: Itatiaia, 1955, Lallemand leg. (BMNH). Parátipos. Minas Gerais: 20', 5\$, Serra do Caraça, III.1963, F. Werner, U. Martins

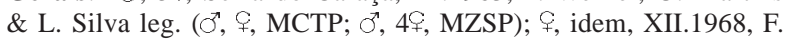
Werner leg. (Coleção M. Alvarenga) (MCTP); Rio de Janeiro: Itatiaia, đ', 5.II.1957, M. A. Vulcano leg. (MZSP); São Paulo: São José do Barreiro (Serra da Bocaina, Fazenda do Bonito), ơ, sem data, M.A. Vulcano leg. (MCTP); Santa Catarina: Hansa (Corupá), 3‡, 1937, J. Clermonte leg. (ZMUC); Itaiópolis, \&, 24.III.1929, A. Maller leg. (BMNH); Rio Grande do Sul: São Francisco de Paula (Pró-Mata), \&, 15-18.III.2001, L. A. Bertoncello leg. (MCTP).

Discussão. A aparência externa, principalmente das tégminas, sugere que esta espécie deveria ser enquadrada no subgênero Ipiranga, porém a conformação do posclípeo e aparência da genitália são características do subgênero tipo. Assemelha-se a Mahanarva (Mahanarva) webbi sp. nov. quanto à morfologia externa, porém a coloração vermelha das tégminas se estende até o início do terço posterior desta e a genitália do macho difere substancialmente.

Etimologia. Epíteto específico alusivo à coloração vermelha das veias da tégmina.

\section{Mahanarva (Mahanarva) webbi sp. nov.} (Figs. 17-24, 42, 45)

Medidas (em mm). o. Comprimento da cabeça, 1; largura da cabeça, 2; diâmetro do ocelo, 0,1 ; distância interocelar, 0,2 ; distância ocelo-olho, 0,4 ; distância ocelotilo, 0,2; distância ocelos-margem posterior, 0,3; distância interocular, 1,2; comprimento do tilo, 0,4 ; largura do tilo, 0,6; comprimento do posclípeo, 1,3; largura do posclípeo, 0,6 ; comprimento do pronoto, 2,3; largura do pronoto, 3,5; comprimento do escutelo, 2,1; largura do escutelo, 1,6; comprimento da tégmina, 9,3; largura da tégmina, 2,6; comprimento total, 11,3.

Diagnose. Coloração geral castanho-avermelhada; tégminas castanho-escuras, com as veias avermelhadas na metade basal e três máculas isoladas desta mesma cor. Tórax e abdômen vermelho-claros com áreas castanhas. Pernas vermelhas, com face interna das tíbias e tarsos enegrecidos (Figs. 42, 45).

Holótipo macho. Cabeça castanho-avermelhada, mais larga que o comprimento do vértice, este carenado e convexo; margens supra-antenais castanhoavermelhadas; tilo quadrangular, duas vezes mais largo do que longo, castanho-escuro, com carena mediana proeminente e bem marcada; ocelos transparentes, separados entre si por mais de um diâmetro de um deles, mais próximos um do outro do que dos olhos e da margem posterior da cabeça; olhos castanho-escuros, com a região periférica mais clara, proeminentes e dispostos transversalmente; antenas com pedicelo negro, mais 

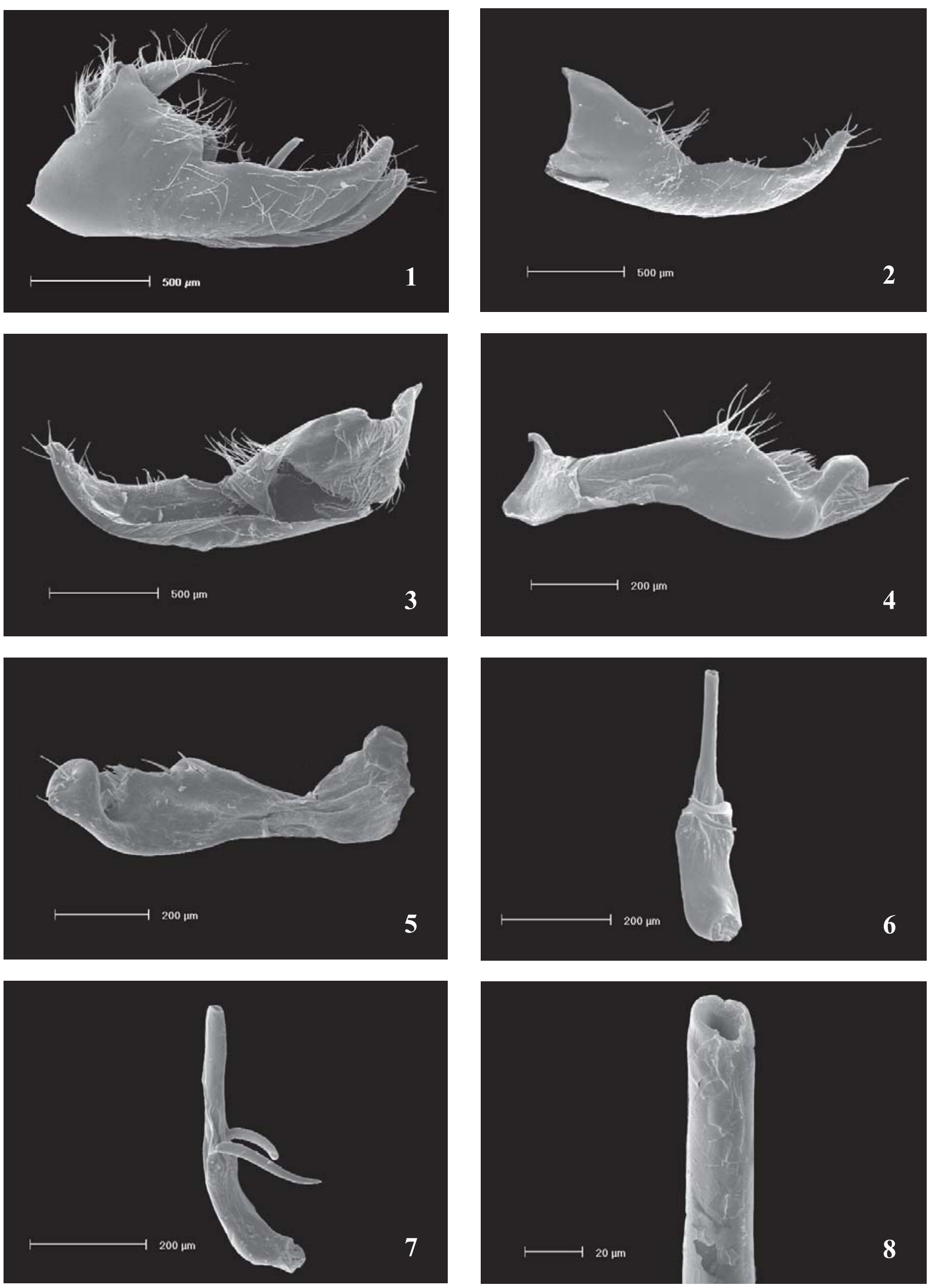

Figs. 1-8. Mahanarva (Mahanarva) rubrovenata sp. nov., §. 1, pigóforo, vista lateral; placa subgenital: 2, vista lateral externa; 3, vista lateral interna; parâmero: 4, vista lateral externa; 5, vista lateral interna; edeago: 6, vista dorsal; 7, vista lateral; 8, ápice. 

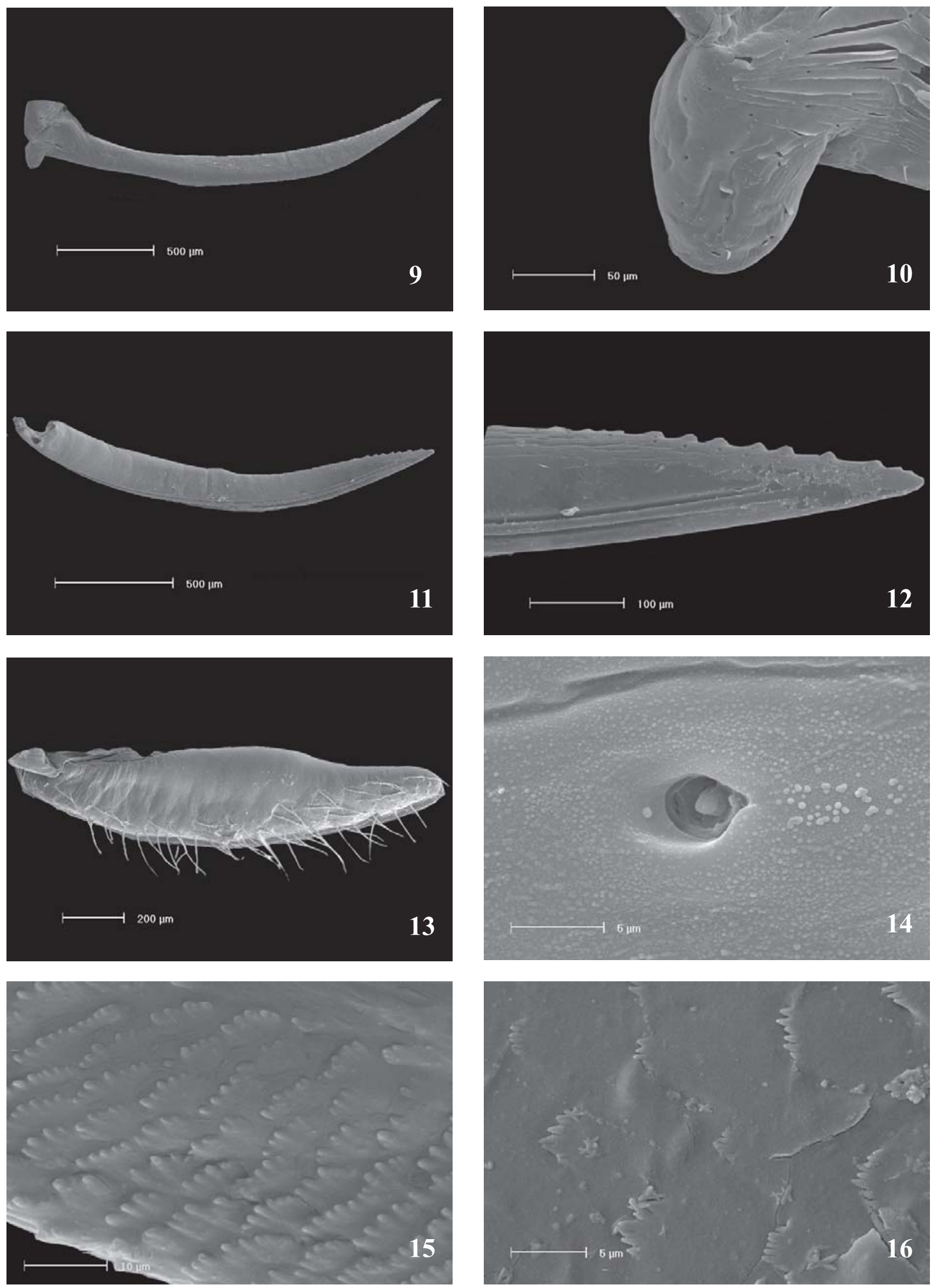

Figs. 9-16. Mahanarva (Mahanarva) rubrovenata sp. nov., .. Ovipositor: 9, primeira valva, vista lateral externa; 10, processo basal, vista lateral; segunda valva: 11, vista lateral externa; 12 , ápice; 13 , terceira valva; 14, sensila da segunda valva; ornamentações internas: 15 , segunda valva; 16 , terceira valva. 
longo que largo, visível dorsalmente, corpo basal do flagelo subcilíndrico, projetado para fora do pedicelo, portando uma arista menor do que este; posclípeo castanho-avermelhado, mais longo que largo, inflado, de perfil angulado, com ranhuras laterais levemente marcadas, carena longitudinal distinta e proeminente formando um triângulo no ápice com o tilo; anteclípeo vermelho com mácula negra na porção mediana, maior que o último artículo do rostro, que é menor que o anterior; rostro atingindo as mesocoxas, com segundo artículo vermelho e o terceiro negro. Pronoto hexagonal, mais largo do que longo, vermelho na metade anterior e marromescuro na posterior, grosseiramente puncturado, com duas impressões na metade anterior e duas menores situadas próximas à linha mediana; carena mediana levemente marcada e mais visível na porção posterior; margem anterior e ântero-laterais retas, póstero-laterais sinuosas com leve concavidade, posterior chanfrada com reentrância mediana, ângulos umerais arredondados; escutelo marrom-escuro, mais longo que largo, com concavidade mediana e sem rugosidades transversais. Tégminas estreitas, finamente puncturadas, castanhoescuras com as veias vermelhas na metade basal e três máculas desta mesma cor: uma na ramificação da veia $\mathrm{R}$, outra na margem anal, no limite entre o terço médio e posterior, e outra na margem costal, no início do terço posterior; $\mathrm{M} \mathrm{e} \mathrm{Cu} 1$ coalescidas na base; reticulação apical bem desenvolvida, veias salientes, A1 e A2 bem distintas. Asas hialinas com venação negra; $\mathrm{Cu} 1$ não espessada na base. Pernas posteriores: fêmur com pequeno espinho na face interna; tíbia com dois espinhos laterais, sendo o basal inconspícuo e menor que os apicais desta, estes em número de 14, dispostos em duas fileiras; basitarso com 17 espinhos apicais em duas fileiras, ocultos por longas cerdas; processo subungueal presente.

Pigóforo castanho-claro, com processos laterais entre o tubo anal e as placas subgenitais (Fig. 17); placa subgenital com ápice arredondado e uma elevação basal munida de pequenos dentículos escamiformes que se estendem longitudinalmente e lateralmente pela face interna (Figs. 18, 19); parâmeros sub-retangulares, com elevação dorsal desenvolvida e ápice arredondado, dente subapical robusto, voltado para fora, com formato de gancho, apresentando um conjunto de dentículos na face ventral (Figs. 20, 21); edeago subcilíndrico, com haste estreita e longa, processos dorsais eqüidistantes da base e ápice, levemente comprimidos lateralmente e curvos apicalmente. (Figs. 22-24).

Material-tipo. Holótipo ơ, BRASIL, Minas Gerais: Águas Claras, XII.1983, Alavarenga leg. (MCTP). Parátipos: 5ळ', idem (2 MCTP, 2 MZSP, 1 BMNH).

Discussão. A aparência externa, principalmente da tégmina, sugere que esta espécie deveria ser enquadrada no subgênero Ipiranga, porém a conformação do posclípeo e aparência da genitália são características do subgênero tipo. Assemelha-se a $M$. (M.) rubrovenata sp. nov., mas o vermelho da tégmina se restringe à metade basal desta, além da diferença nas peças da genitália do macho.

Etimologia. O epíteto é uma homenagem a Michael D. Webb, curador de Hemiptera do BMNH.
Mahanarva (Mahanarva) dabliosignata sp. nov.

(Figs. 25-40, 43, 46)

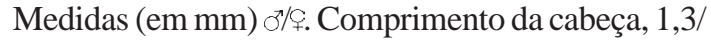
1,1 ; largura da cabeça, 2,3/2,6; diâmetro do ocelo, $0,1 / 0,1$; distância interocelar, 0,3/0,3; distância ocelo-olho, 0,5/ 0,5; distância ocelo-tilo, 0,2/0,2; distância ocelos-margem posterior, $0,2 / 0,3$; distância interocular, 1,8/1,7; comprimento do tilo, 0,3/0,3; largura do tilo, $0,6 / 0,8$; comprimento do posclípeo, 1,4/1,4; largura do posclípeo, 0,7/0,9; comprimento do pronoto, 2,2/2,4; largura do pronoto, 3,8/4,5; comprimento do escutelo, 2/2; largura do escutelo, 2/2; comprimento da tégmina, 7,8/8; largura da tégmina, 2,8/3,1; comprimento total, 9,7/10,2.

Diagnose. Coloração geral castanho-avermelhada com duas faixas alaranjadas, dispostas transversalmente sobre as tégminas, sendo a anterior em "zigue-zague" e a posterior reta. Tórax castanho-avermelhado, abdômen castanho-escuro com as margens vermelhas. Pernas castanho-avermelhadas (Figs. 43, 46).

Holótipo macho. Cabeça avermelhada, mais larga que o comprimento do vértice, este carenado e convexo; margens supra-antenais avermelhadas; tilo quadrangular, 1,8 vez mais largo que longo, castanho-avermelhado, com carena mediana fracamente marcada; ocelos transparentes, separados entre si por mais de um diâmetro de um deles, mais próximos um do outro do que dos olhos e da margem posterior da cabeça; olhos castanho-escuros, com a região periférica mais clara, proeminentes e dispostos transversalmente; antenas com pedicelo avermelhado, mais longo do que largo, não visível dorsalmente; corpo basal do flagelo subcilíndrico, castanho, projetado para fora do pedicelo, portando uma arista menor do que este; posclípeo avermelhado, inflado, de perfil angulado, mais longo que largo, com ranhuras laterais grosseiramente marcadas, carena longitudinal distinta, não formando um triângulo no ápice com o tilo; anteclípeo castanho-avermelhado, maior que o último artículo do rostro, que é menor que o anterior; rostro castanho-avermelhado, atingindo as coxas medianas; pronoto hexagonal, mais largo que longo, castanhoavermelhado, grosseiramente puncturado, recoberto por uma fina pubescência dourada, com carena mediana levemente marcada, mais visível na porção posterior; margem anterior reta, ântero-laterais convexas, pósterolaterais sinuosas com leve concavidade e posterior chanfrada com reentrância mediana; ângulos umerais arredondados; escutelo vermelho, mais longo que largo, com concavidade mediana e rugosidades transversais. Tégmina larga, finamente puncturada, castanho-clara com a margem anal avermelhada, ornada com duas faixas transversais alaranjadas: a anterior entre o terço anterior e o terço médio, formando um "zigue-zague" e a posterior disposta entre o terço médio e o posterior; $\mathrm{M}$ e $\mathrm{Cu} 1$ coalescidas na base; reticulação apical bem desenvolvida; veias visíveis, duas veias anais, sendo A2 pouco aparente. Asas hialinas com venação castanha, $\mathrm{Cu} 1$ levemente espessada na base. Pernas posteriores: fêmur com pequeno espinho na face interna; tíbia com dois espinhos laterais, sendo o basal de igual tamanho 

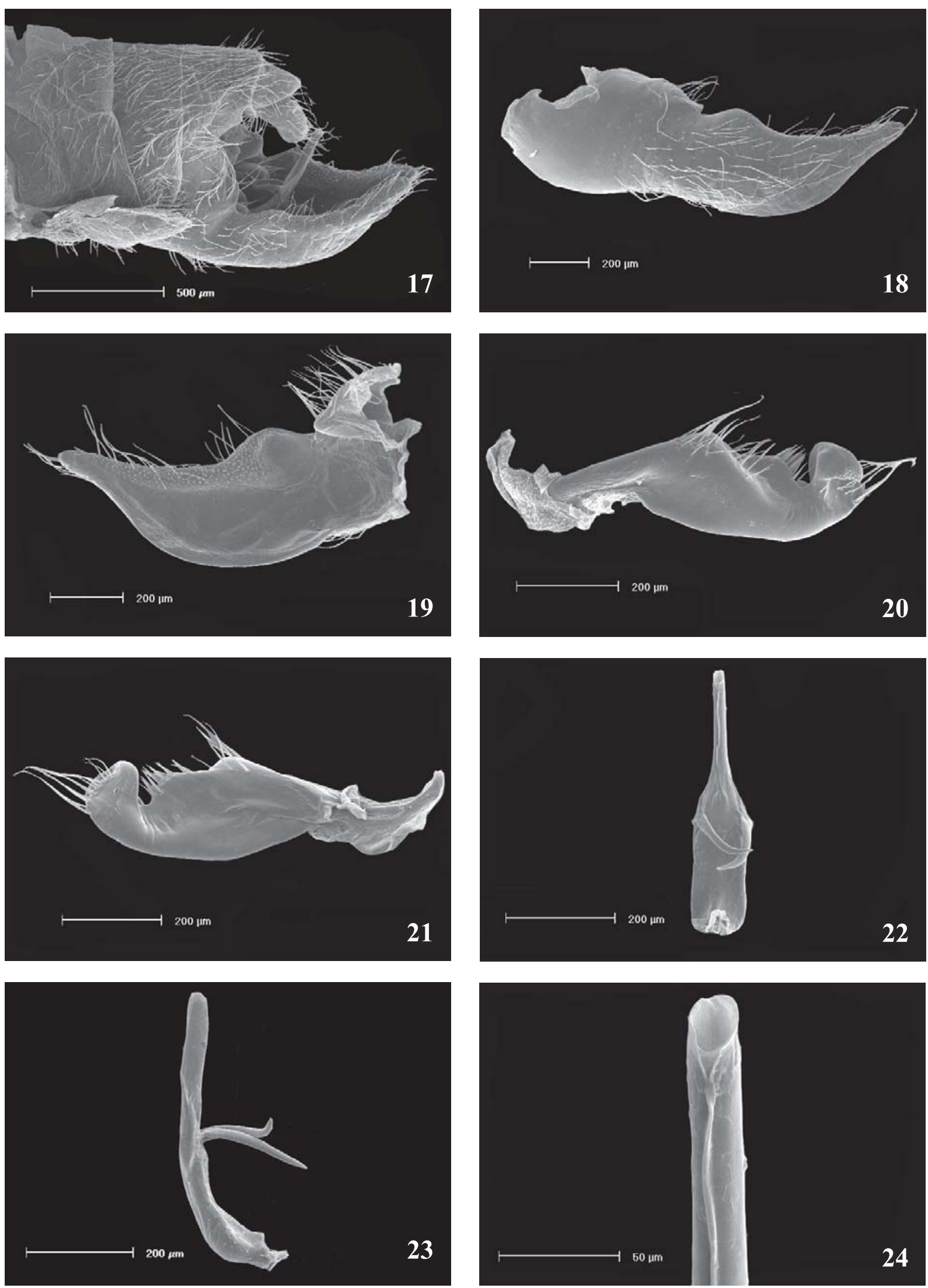

Figs. 17-24. Mahanarva (Mahanarva) webbi sp. nov., o'. 17, pigóforo, vista lateral; placa subgenital: 18, vista lateral externa; 19, vista lateral interna; parâmero: 20, vista lateral externa; 21 , vista lateral interna; edeago: 22, vista dorsal; 23, vista lateral; 24, ápice. 

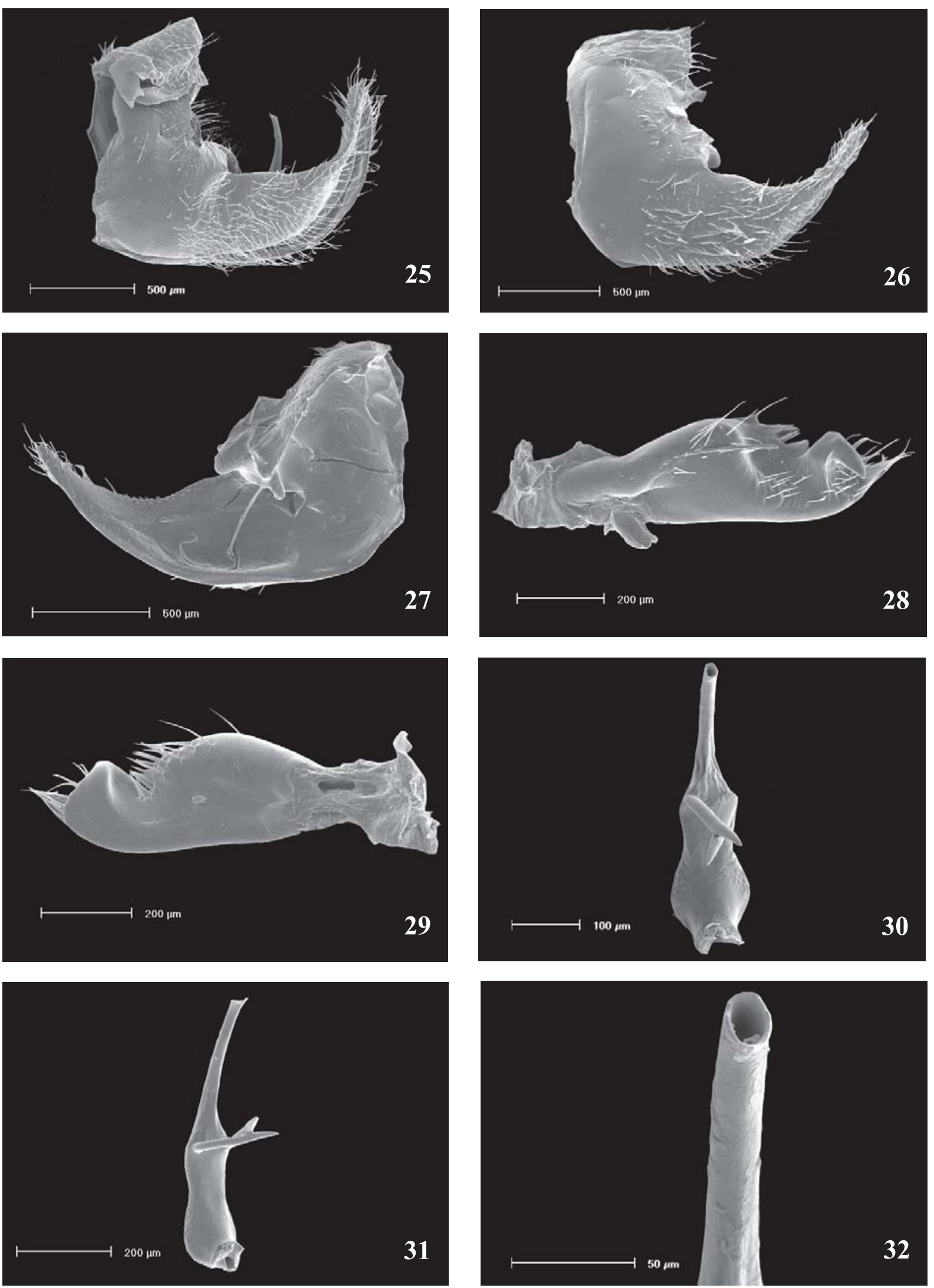

Figs. 25-32. Mahanarva (Mahanarva) dabliosignata sp. nov., o'. 25, pigóforo, vista lateral; placa subgenital: 26, vista lateral externa; 27, vista lateral interna; parâmero: 28, vista lateral externa; 29, vista lateral interna; edeago: 30, vista dorsal; 31, vista lateral; 32, ápice. 

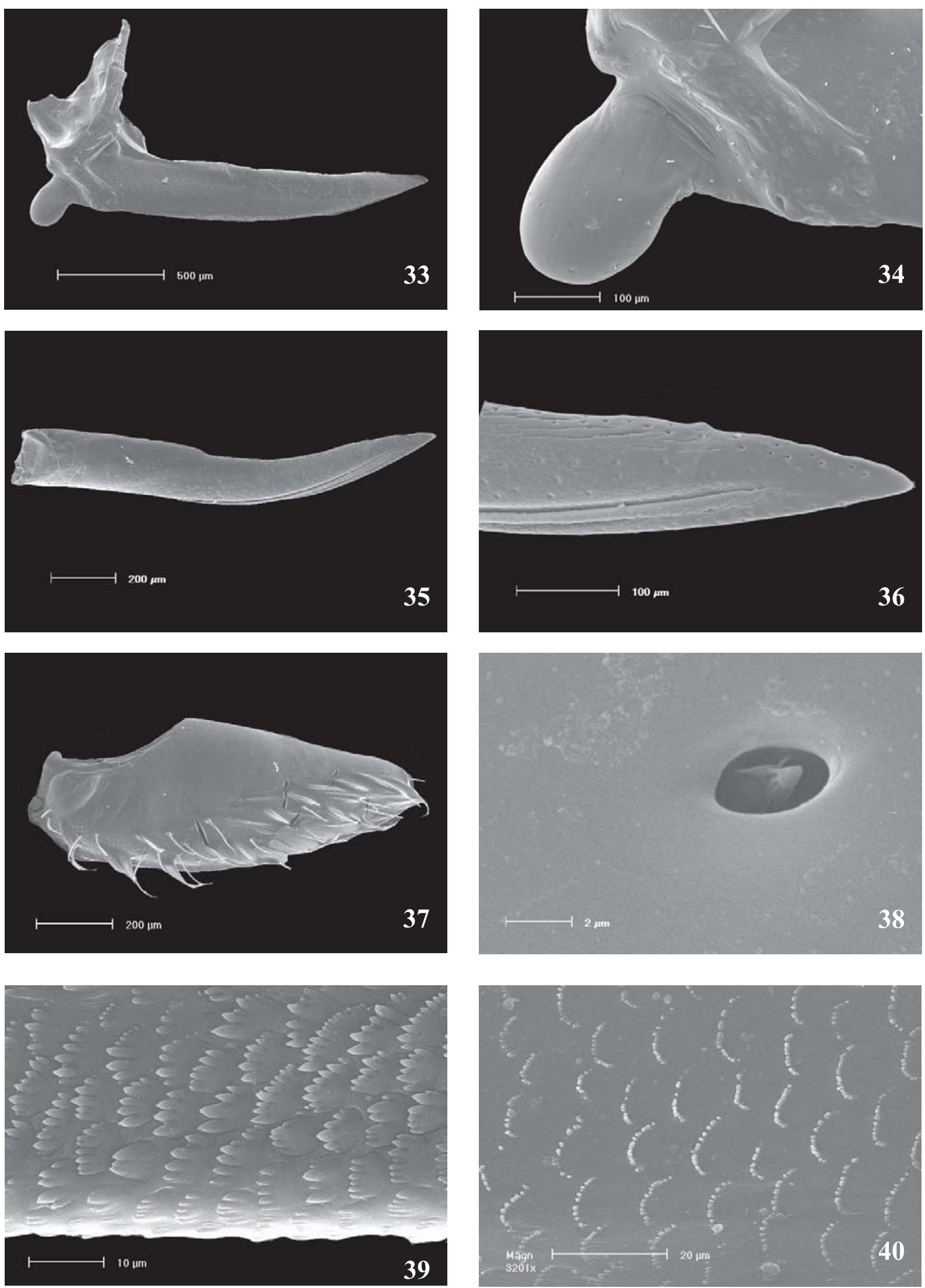

Figs. 33-40. Mahanarva (Mahanarva) dabliosignata sp. nov., ․ Ovipositor: 33, primeira valva, vista lateral externa; 34, processo basal, vista lateral; segunda valva: 35 , vista lateral externa; 36, ápice; 37 , terceira valva; 38 , sensila da segunda valva; ornamentações internas: 39 , segunda valva; 40 , terceira valva. 
dos apicais desta, estes em número de 13 , dispostos em duas fileiras; basitarso com 15 espinhos apicais distribuídos em duas camadas, cobertos por longas cerdas; processo subungueal presente.

Pigóforo castanho-amarelado, com processos arredondados entre o tubo anal e as placas subgenitais (Fig. 25), estas largas na base e afuniladas em direção ao ápice, que é arredondado e voltado para cima; margem dorsal com fileiras de dentículos pontiagudos na face interna, mais abundantes próximo ao ápice (Figs. 26, 27); parâmeros sub-retangulares, com elevação dorsal desenvolvida, ápice arredondado, dente subapical voltado para fora, em forma de foice (Figs. 28, 29); edeago subcilíndrico, com haste delgada e longa, ápice acuminado, processos dorsais retos e inseridos um pouco abaixo da metade (Figs. 30-32).

Fêmea. Semelhante ao macho, um pouco maior, com posclípeo acentuadamente angulado. Ovipositor com a primeira valva curta com ápice acuminado (Fig. 33), processo basal desenvolvido, arredondado, em forma de colher, disposto obliquamente (Fig. 34); segunda valva curta, com ápice inconspicuamente serrilhado no terço anterior (Figs. 35, 36), portando um conjunto de sensilas na face externa (Fig. 38) e ornamentações laminares na face interna (Fig. 39); terceira valva curta e larga, com um conjunto de cerdas na porção inferior (Fig. 37) e ornamentações em sua face interna (Fig. 40).
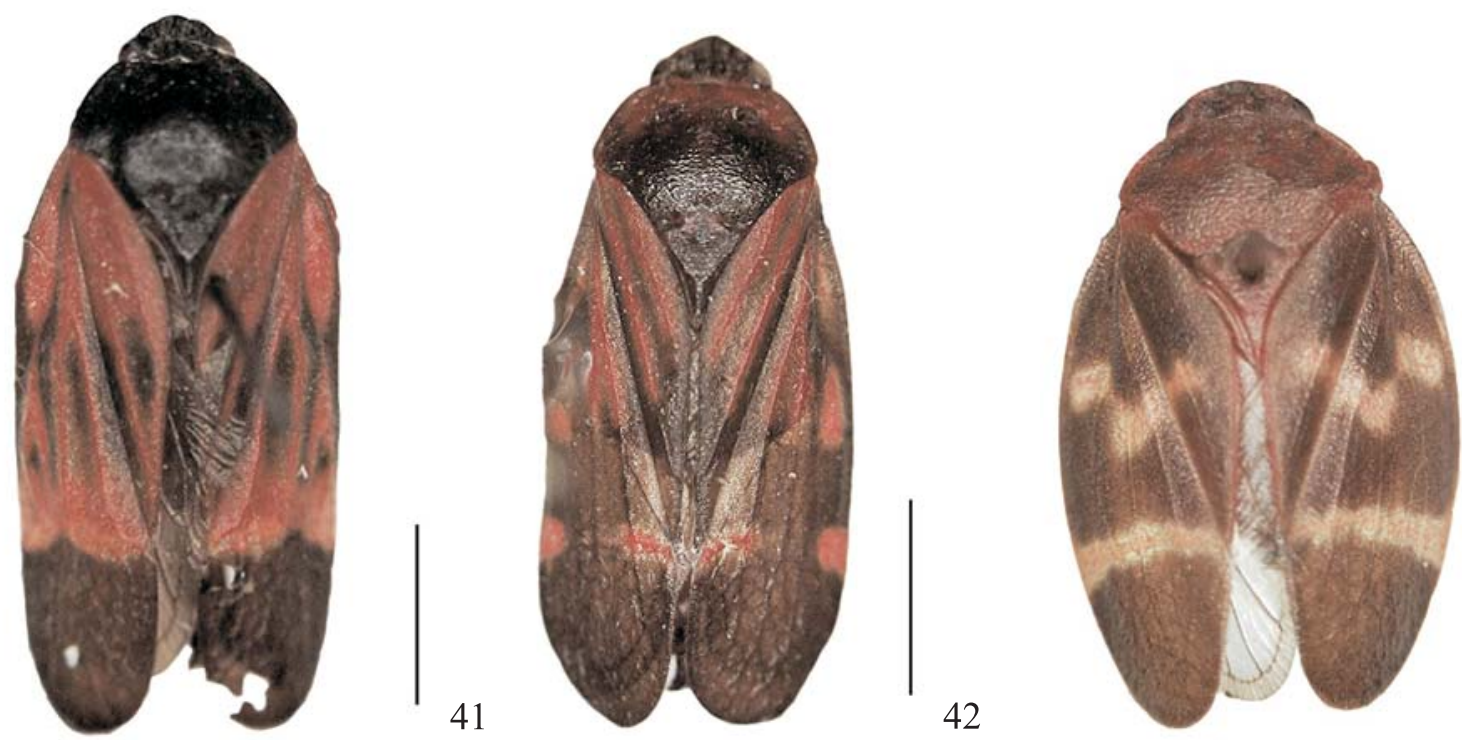

Figs. 41-43. Holótipos $\sigma$, vista dorsal: 41, Mahanarva (Mahanarva) rubrovenata sp. nov.; 42, Mahanarva (Mahanarva) webbi sp. nov.; 43, Mahanarva (Mahanarva) dabliosignata sp. nov. Escala $=3 \mathrm{~mm}$.

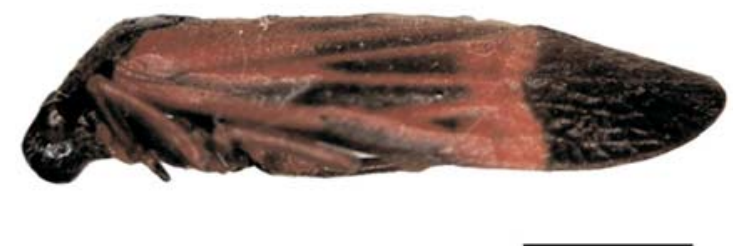

44

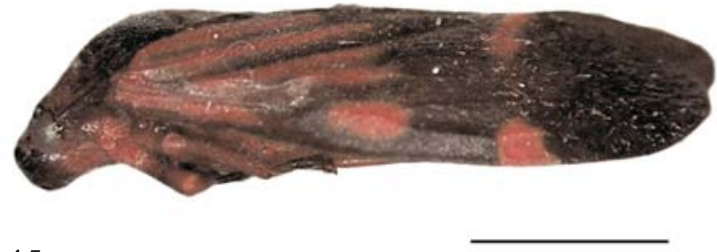

45

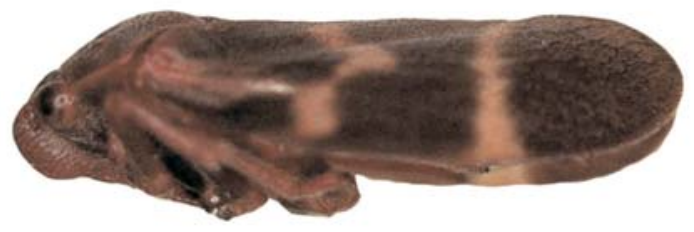

46

Figs. 44-46: Holótipos ơ, vista lateral: 44, Mahanarva (Mahanarva) rubrovenata sp. nov.; 45, Mahanarva (Mahanarva) webbi sp. nov.; 46, Mahanarva (Mahanarva) dabliosignata sp. nov. Escala $=3 \mathrm{~mm}$. 
Material-tipo. Holótipo đ̋, BRASIL, Paraná: Guarapuava (Est. Águas Sta. Clara), 1.X.1986, Lev. Ent. PROFAUPAR leg. (DZUP). Parátipos: 20', mesmos dados do holótipo (DZUP); Rio Grande do Sul: $\circlearrowleft$, Derrubadas (Parque Estadual do Turvo, $\left(27^{\circ} 12\right.$ '38,5”S; 53 51 '15,3”W), 20.X.2004, A. Barcellos, R. Ot \& I. Heydrich col.;, , idem, (Estrada para Yucumã), L. Moura col.; \&, idem, $\left(27^{\circ} 14^{\prime} 48,9^{\prime}\right.$ 'S; 535 $\left.57^{\prime} 36,7^{\prime \prime} \mathrm{W}\right), 28 . X .2003$, L. Moura col.; f, idem, (27 9'53,3”S; 53 52 '006”W), A. Barcellos,

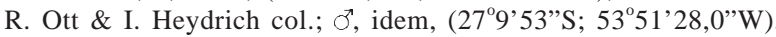
21.X.2004, A. Barcellos, R. Ott \& I. Heydrich col.; ơ, Itaúba, 27.X.1999, Franceschini, Bonaldo \& Silva col. (MCNZ); † Pareci (=Parecy) Novo, IX.1932, Pe. Buck leg. (MCTP); Ф, São Francisco de Paula (Pró-Mata), 19-20.XI.1998, Carvalho \& Pulz leg. (MCTP); \&, Porto Alegre, 31.X.1951, Pe. Buck leg. (MCTP); idem, 8.XI.1955. (MCTP).

Discussão. Assemelha-se a $M$. (M.) consita (Melichar, 1915), porém é mais avermelhada e menor, além da diferença nas peças da genitália do macho; as fêmeas possuem coloração menos avermelhada, com a faixa em "zigue-zague" nas tégminas pouco aparente.
Etimologia. Epíteto específico alusivo à faixa em "zigue-zague", a qual lembra a letra "w" sobre as tégminas.

Agradecimentos. Ao Conselho Nacional de Desenvolvimento Científico e Tecnológico (CNPq), pela concessão da bolsa de estudos ao primeiro autor. À Miriam Souza dos Santos, do Centro de Microscopia e Microanálises (CEMM) da PUCRS, pelo apoio na manipulação do MEV. À equipe do Laboratório de Malacologia da PUCRS, pelo auxílio e empréstimo do equipamento fotográfico.

\section{REFERÊNCIAS BIBLIOGRÁFICAS}

Carvalho, G. S. \& WebB, M. D. 2005. Cercopid spittlebugs of the New World (Hemiptera, Auchenorryncha, Cercopidae). Sofia, Pensoft. $271 \mathrm{p}$.

Distant, W. L. 1909. Rhynchotal Notes - XLVI. Annals and Magazine of Natural History 3(8):187-213.

Fennah, R. G. 1968. Revisionary notes on the New World genera of cercopid froghoppers (Homoptera: Cercopoidea). Bulletin of Entomological Research 58(1):165-190.

Recebido em abril de 2006. Aceito em agosto de 2006. ISSN 0073-4721 Artigo disponível em: www.scielo.br/isz 